\title{
The variability of the mitral valve anatomy and terminology
}

\author{
Manuel J. Antunes, MD, PhD, DSc
}

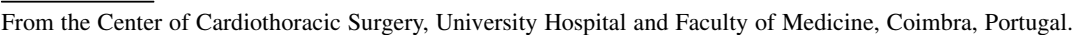 \\ Disclosures: Author has nothing to disclose with regard to commercial support. \\ Received for publication Dec 30, 2017; accepted for publication Jan 10, 2018; available ahead of print Feb 17, \\ 2018. \\ Address for reprints: Manuel J. Antunes, MD, PhD, DSc, Center of Cardiothoracic Surgery, Centro Hospitalar \\ Universitário de Coimbra, Praceta Professor Mota-Pinto, 3000-075 Coimbra, Portugal (E-mail: antunes.cct. \\ chuc@sapo.pt). \\ J Thorac Cardiovasc Surg 2018;155:2011-2 \\ $0022-5223 / \$ 36.00$ \\ Copyright (c) 2018 by The American Association for Thoracic Surgery \\ https://doi.org/10.1016/j.jtcvs.2018.01.028
}

Profound knowledge of the anatomy of the heart and of its constituents is an essential tool for the cardiac surgeon. This is especially true when valve repair surgery is performed. The mitral valve apparatus is particularly complex, and the interaction of its components, the annulus, leaflets, chordae tendineae, and papillary muscles (PMs), is fundamental for competence of the valve, the main goal of the repair.

In this issue of the Journal, Krawczyk-Ożóg and colleagues $^{1}$ from Krakow, Poland, describe the anatomy of the mitral subvalvular apparatus. In an earlier publication, the same group had dealt with the morphologic variability of the mitral valve leaflets, as observed in 200 normal hearts. ${ }^{2}$ In the current article, the description of the different types of PMs and chordae tendineae was based on the analysis of 100 autopsied human hearts from healthy donors. Their intention was "to characterize morphological variations of the PM and chordae tendineae of the left ventricle and ventricular zones of the mitral valve leaflets" and concluded that "there is a high variability in the PMs and tendinous cords in the mitral valve complex."

This is an excellent and pedagogic piece of work that I enjoyed reading. I have even learned some things. For example, "cords to left ventricular outflow tract were present in 14 specimens." These are described as "false cords, based on their attachment to the left ventricle septal wall in the LVOT area, arising from the papillary muscle." The authors state that "they do not seem to have a physiological role. However, they may significantly impede transcatheter procedures." I have seen such chords in several of the thousands of patients I operated on but was far from imagining that they are present in $14 \%$ of the cases.

The variability of the chordal (and PM) anatomy is also well known, but the authors' study helps us to understand the patterns, which are usually not precisely described in the common anatomy books. Contrary to what is commonly believed, the authors think that "strut cords have no direct influence on valve coaptation, but they play an important role in the tunnel-shaped configuration of the valve at the inflow and outflow tracts." Furthermore, in this study they found that "the number of strut cords is highly variable,

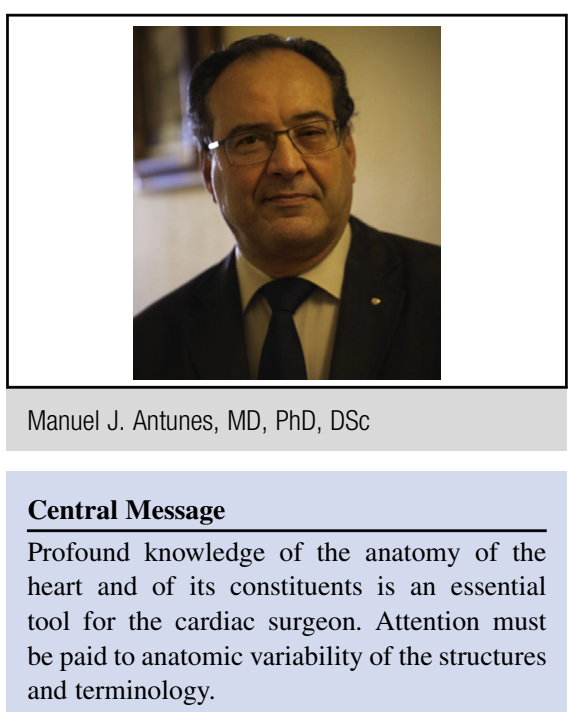

See Article page 2002.

and in some cases, there are no strut cords arising from one or both PM groups. Lack of symmetry in the numbers of strut cords could potentially cause lower control of the AML motion during cardiac cycle and predispose to regurgitation." Another surprise....

This article does not deal only with anatomic variations. Variability of terminology is also a problem one encounters when reading different authors. ${ }^{3}$ In the present work, Krawczyk-Ożóg and colleagues ${ }^{1}$ use the terms "superolateral" and "inferoseptal" to designate the PM (also for the commissures). Most of us are used to the terms "anterolateral" and "posteromedial PM." Questioned about this during the reviewing process, the authors replied (and added to the text) that "the papillary muscles groups are incorrectly described as being located posteromedial and anterolateral, none of the muscles is located more anteriorly or posteriorly." Actually, the terms "anterolateral" and "posteromedial PM" were also used by Dr Anderson and colleagues ${ }^{4}$ in their Editorial Commentary accompanying the cited article on the leaflets' anatomy by the same authors. ${ }^{4}$ On the other hand, Dr Anderson and colleagues ${ }^{4}$ insist on the terms "aortic and mural leaflets" to designate the anterior and posterior leaflets, which most of us use and are used by Krawczyk-Ożóg and colleagues.

With regard to the anatomy of the PMs, the variability is such (they are as "unique as fingerprints") that the authors found it impossible to suggest a classification. They explain this wide variability by "aberrations" of the delamination of the ventricular musculature. These variations may have 
an impact on the function of the mitral valve and on the left ventricular outflow tract blood dynamics.

Finally, during surgery, I have found several cases of complete absence of commissural chordae of the posteromedial commissure, not related to any pathologic process, usually causing regurgitation. Apparently, KrawczykOżóg and colleagues ${ }^{1}$ have not seen such "anatomical variation." May it be that others have also seen it?

This work by Krawczyk-Ożóg and colleagues ${ }^{1}$ is an important piece of anatomic work, of significant pedagogic value, and worth reading thoroughly and will constitute a valuable tool for cardiac surgeons, especially those interested in mitral valve repair.

\section{References}

1. Krawczyk-Ożóg A, Hołda MK, Bolechała F, Siudak Z, Sorysz D, Dudek D, et al. Anatomy of the mitral sub-valvular apparatus. J Thorac Cardiovasc Surg. 2018; 155:2002-10.

2. Krawczyk-Ożóg A, Hołda MK, Sorysz D, Koziej M, Siudak Z, Dudek D, et al. Morphologic variability of the mitral valve leaflets. J Thorac Cardiovasc Surg. 2017; 154:1927-35.

3. Loukas M, Aly I, Tubbs RS, Anderson RH. The naming game: a discrepancy among the medical community. Clin Anat. 2016;29:285-9.

4. Anderson RH, Spicer DE, Mori S. How best to describe the episcopal miter? J Thorac Cardiovasc Surg. 2017;154:1936-7. 